http://jmscr.igmpublication.org/home/ ISSN (e)-2347-176x ISSN (p) 2455-0450

crossref DOI: https://dx.doi.org/10.18535/jmscr/v7i10.01

\author{
Journal Of Medical Science And Clinical Research \\ IGM Publication \\ An official Publication of IGM Publication
}

\title{
A Clinical Study of acute Hypertensive urgency and Hypertensive Emergency in a Teaching Hospital
}

\author{
Author \\ Dr P Mallesham* \\ Associate Professor, Department of General Medicine, Prathima Institute of Medical Sciences, Nagunoor, \\ Karimnagar \\ *Corresponding Author \\ Dr P Mallesham \\ Sri Thirumala Hospital, Opp Congress Office, Near Police Station, Peddapalli-505172, Telangana State
}

\begin{abstract}
Hypertension is a growing problem of the century and over the last decade, the number of young patients with hypertension is found to be increasing. The incidence of hypertensive crisis is also found to be increasing. We in the present study tried to evaluate the clinical and epidemiological characteristics of hypertensive emergency presenting to our teaching hospital.

Methods: This prospective cross-sectional study was conducted in the Department of General Medicine, Prathima Institute of Medical Sciences, Nagunur, Karimnagar. Prior Institutional Ethical committee permission was obtained for the study. Written consent was obtained from all the participants of the study. Inclusion criteria were adult patients $>31$ years of both sexes who were admitted to medical or emergency ICU with blood pressure readings of $>180 / 120 \mathrm{mmHg}$. A detailed Clinical examination was done were fundoscopy, including ophthalmic examination; neurological deficits if any were identified. Laboratory investigations were done which includes hemoglobin, erythrocyte sedimentation rate [ESR], complete blood count, Renal function tests (serum urea, serum creatinine, and electrolytes), Liver function tests, serum lipid profile, serum calcium, serum phosphorus serum uric acid, Electrocardiogram, 2D Echocardiogram, PA chest radiograph.

Results: The mean values of diastolic blood pressure at the time of admission in hypertensive urgency were found to be $122.55 \mathrm{mmHg}$ and the mean values after treatment were $88.46 \mathrm{mmHg}$ a mean change of $34 \mathrm{mmHg}$. In the hypertensive emergency group, the mean values at the time of admission were 130.83 $\mathrm{mmHg}$ and at the time of discharge, the values were $89.06 \mathrm{mmHg}$ a mean change of $41 \mathrm{mmHg}$.

Conclusion: the hypertensive crisis is found more commonly in the $6^{\text {th }}$ to $7^{\text {th }}$ decade of age. There is the tendency of males to have a higher incidence of hypertensive crisis. Known hypertensive with some degree of target organ damage is more associated with hypertensive emergencies. Therefore strict blood pressure control and regular evaluation of the patients is necessary to prevent morbidity and mortality due to hypertensive crisis.
\end{abstract}

Keywords: Hypertensive urgency, Hypertensive Emergency, Hypertensive crisis.

\section{Introduction}

Hypertension is one leading cause of morbidity, mortality and contributes immensely to the global burden of diseases. It has been estimated that approximately 7.5 million deaths about $12.8 \%$ of the total of all deaths. This also accounts for 57 
million disability-adjusted life years or 3.7 of total DALYS ${ }^{[1]}$. Hypertension doubles for the risk of cardiovascular disease, including coronary heart disease, ischemia, and hemorrhagic stroke, renal failure, and peripheral arterial disease ${ }^{[2]}$. The common symptoms of patients in a hypertensive emergency with acute target organ damage are dyspnoea, chest pain, giddiness, focal neurological deficits and loss of vision ${ }^{[3]}$. The examination of patients must, therefore, include evaluation of these symptoms to exclude hypertensive emergencies ${ }^{[3]}$. Blood pressure in certain cases may increase rapidly and severely enough which is called Hypertensive crises. Hypertensive crisis is further divided into hypertensive urgency and hypertensive emergency ${ }^{[4]}$. Hypertensive emergency is a situation where there is a severe elevation of Blood pressure (>180/120 mmHg) complicated by evidence of impending or progressive target organ dysfunction. Hypertensive urgencies are those situations associated with severe elevations in BP without progressive target organ dysfunction ${ }^{[4]}$. Incidence of hypertension in the young population is increasing by the day because of a sedentary lifestyle, dietary pattern, and smoking. The prevalence of hypertension generally increases with age and more than $50 \%$ of people between age group 60-69 years will suffer from it and up to $75 \%$ of age group above 70 will be affected by hypertension ${ }^{[5]}$. Improved diagnostic criteria and management has lead to better treatment of chronic hypertension and thus has decreased the lifetime incidence of hypertensive crisis to less than $1 \%$ of the patients with severe hypertension $^{[6]}$. Generally, hypertensive emergency will the result of non-compliance to drugs or new presentation of unrecognized essential hypertension. A hypertensive emergency is characterized by rapid deterioration of target organ function and may endanger the life if not treated immediately ${ }^{[7]}$. Therefore with the increase in the burden of hypertension among the population, we in the present study tried to evaluate the underlying factors for hypertensive crisis and treatment and outcome in the patients visiting our tertiary care and teaching hospital.

\section{Material and methods}

This prospective cross-sectional study was conducted in the Department of General Medicine, Prathima Institute of Medical Sciences, Nagunur, Karimnagar. Prior Institutional Ethical committee permission was obtained for the study. Written consent was obtained from all the participants of the study. Inclusion criteria were adult patients $>31$ years of both sexes who were admitted to medical or emergency ICU with blood pressure readings of $>180 / 120 \mathrm{mmHg}$. Exclusion criteria: Pregnant females, patients with a history of myocardial infarction, patients unwilling to participate in the study. The selected subjects were classified as hypertensive urgency or hypertensive emergency as per JNC VII criteria. A thorough history including age, personal habits, socio-economic status, and occupation, diabetes, other medical conditions were noted. A detailed Clinical examination was done were fundoscopy, including ophthalmic examination; neurological deficits if any were identified. Laboratory investigations were done which includes hemoglobin, erythrocyte sedimentation rate [ESR], complete blood count, Renal function tests (serum urea, serum creatinine, and electrolytes), Liver function tests, serum lipid profile, serum calcium, serum phosphorus serum uric acid, Electrocardiogram, 2D Echocardiogram, PA chest radiograph. Patients with hypertensive emergencies were assessed for target organ damage like LVF, unstable angina, encephalopathy, and glomerulonephritis. All the data collected was recorded in MS Excel spreadsheet and analyzed using SPSS version 17 software on windows format.

\section{Results}

The study involved cases of hypertensive urgency $(n=27)$ and hypertensive emergency $(n=20)$. Out of the $\mathrm{n}=27$ hypertensive urgency cases, $\mathrm{n}=18(66.66 \%)$ were male patients and 


\section{JMSCR VoI||07||Issue||10||Page 01-06||October}

$\mathrm{n}=9(33.33 \%)$ were female patients the age-wise distribution showed most of the cases were between age group 61-70 years $n=8(29.62 \%)$. In the hypertensive emergency cases out of $n=20$ $\mathrm{n}=13(65 \%)$ cases were males and $\mathrm{n}=7(35 \%)$ were females and most of the cases $n=8(40 \%)$ were among the age group $>70$ years. The other details regarding the demographic characteristics of the cases in the study are shown in table 1.

Table 1: showing the age and gender wide distribution of the cases in the study

\begin{tabular}{|l|c|c|c|c|c|c|}
\hline \multirow{2}{*}{$\begin{array}{l}\text { Age group } \\
\text { years }\end{array}$} & \multicolumn{3}{|c|}{ Hypertensive urgency $(\mathbf{n}=\mathbf{2 7})$} & \multicolumn{3}{c|}{ Hypertensive Emergency $(\mathbf{n}=\mathbf{2 0})$} \\
\cline { 2 - 7 } & Male & Female & Total $(\%)$ & Male & Female & Total $(\%)$ \\
\hline $\mathbf{3 1 - 4 0}$ & 3 & 1 & $4(14.81)$ & 2 & 0 & $2(10)$ \\
\hline $\mathbf{4 1 - 5 0}$ & 2 & 3 & $5(18.51)$ & 3 & 1 & $4(20)$ \\
\hline $\mathbf{5 1 - 6 0}$ & 5 & 2 & $7(25.92)$ & 1 & 2 & $3(15)$ \\
\hline $\mathbf{6 1 - 7 0}$ & 6 & 2 & $8(29.62)$ & 2 & 1 & $3(15)$ \\
\hline$>\mathbf{7 0}$ & 2 & 1 & $3(11.11)$ & 5 & 3 & $8(40)$ \\
\hline Total & 18 & 9 & $27(100)$ & 13 & 7 & $20(100)$ \\
\hline
\end{tabular}

The predominant symptoms of the patients on presentation were evaluated in both the groups. The most common symptom of cases in hypertensive urgency group was giddiness in $\mathrm{n}=17(62.96 \%)$ followed by headache in $\mathrm{n}=15(55.56 \%)$. In the hypertensive emergency, group headache was found in $\mathrm{n}=11(55 \%)$ and giddiness was found in $n=9(45 \%)$. A comparison of the results found the p-value to be significant for giddiness $\mathrm{p}(<0.05)$. The other symptoms in the cases of the study and $p$ values are given in table 2 .

Table 2: showing the predominant symptoms in the patients of the study

\begin{tabular}{|l|c|c|c|}
\hline Symptoms & $\begin{array}{c}\text { Hypertensive Urgency } \\
\mathbf{N = 2 7}\end{array}$ & $\begin{array}{c}\text { Hypertensive Emergency } \\
\mathbf{N = 2 0}\end{array}$ & P-value \\
\hline Headache & $15(55.56 \%)$ & $11(55.0 \%)$ & 0.25 \\
\hline Giddiness & $17(62.96 \%)$ & $9(45.0 \%)$ & $<0.05^{*}$ \\
\hline Dyspnoea & $5(18.51 \%)$ & $8(40.0 \%)$ & 0.1 \\
\hline Chest Pain & $3(11.11 \%)$ & $5(25.0 \%)$ & 0.23 \\
\hline Epistaxis & $6(22.22 \%)$ & $9(45.0 \%)$ & 0.6 \\
\hline Visual Blurring & $1(3.7 \%)$ & $2(10.0 \%)$ & 0.81 \\
\hline Oliguria & $0(0.0 \%)$ & $4(20.0 \%)$ & - \\
\hline Focal Neurological Deficits & $0(0.0 \%)$ & $7(35.0 \%)$ & - \\
\hline Seizures & $0(0.0 \%)$ & $2(10.0 \%)$ & - \\
\hline
\end{tabular}

The most common risk factor in the cases of hypertensive urgency was dyslipidemia in $\mathrm{n}=5(18.51 \%)$, followed by diabetes mellitus in $\mathrm{n}=3(11.11 \%)$. Similarly, in hypertensive emergencies, the common risk factor was diabetes mellitus followed by dyslipidemia in $\mathrm{n}=6(30 \%)$ of cases. The $\mathrm{p}$ values were found to be significant for Diabetes mellitus between both the groups. The other risk factors and distribution is shown in table 3 .

Table 3: Showing the risk factors in the cases of the study

\begin{tabular}{|c|c|c|c|}
\hline Etiology & $\begin{array}{c}\text { Hypertensive urgency } \\
\mathrm{N}=27 \\
\end{array}$ & $\begin{array}{c}\text { Hypertensive Emergency } \\
\text { N =20 }\end{array}$ & P-value \\
\hline Diabetes Mellitus & $3(11.11 \%)$ & $7(35 \%)$ & $<0.05^{*}$ \\
\hline Dyslipidemia & $5(18.51 \%)$ & $6(30 \%)$ & 0.2 \\
\hline Alcohol consumption & $2(7.4)$ & $2(10 \%)$ & 0.33 \\
\hline Tobacco chewing & $0(0.0)$ & $1(5 \%)$ & 1.6 \\
\hline Smoking & $1(3.7 \%)$ & $2(10 \%)$ & 0.59 \\
\hline
\end{tabular}

*Significant 
The mean values of systolic blood pressure at the time of admission in hypertensive urgency were found to be $192.55 \mathrm{mmHg}$ and at the time of discharge, it was $136.46 \mathrm{mmHg}$ a mean change of $56 \mathrm{mmHg}$. In the hypertensive emergency group, the mean values at the time of admission were $201.02 \mathrm{mmHg}$ and at the time of discharge, the values were $139.43 \mathrm{mmHg}$ a mean change of $62 \mathrm{mmHg}$. The SBP recordings during various stages of treatment are shown in table 4.

Table 4: Showing the recording of Systolic Blood pressure during various stages of treatment

\begin{tabular}{|l|c|c|c|c|}
\hline \multirow{2}{*}{$\begin{array}{l}\text { SBP recordings during } \\
\text { various stages of treatment }\end{array}$} & \multicolumn{2}{|c|}{$\begin{array}{c}\text { Hypertensive urgency } \\
(\mathbf{N = 2 7})\end{array}$} & \multicolumn{2}{c|}{$\begin{array}{c}\text { Hypertensive Emergency } \\
(\mathbf{N}=20)\end{array}$} \\
\cline { 2 - 5 } & $\begin{array}{c}\text { Mean Systolic } \\
\text { Blood pressure } \\
\mathbf{m m H g}\end{array}$ & $\begin{array}{c}\text { Standard } \\
\text { deviation }\end{array}$ & $\begin{array}{c}\text { Mean Systolic } \\
\text { Blood pressure } \\
\text { mmHg }\end{array}$ & $\begin{array}{c}\text { Standard } \\
\text { deviation }\end{array}$ \\
\hline At the time of admission & 192.55 & 20.56 & 201.02 & 22.68 \\
\hline After one hour & 182.10 & 18.55 & 189.33 & 19.89 \\
\hline At the end of 24 hours & 160.23 & 11.07 & 166.5 & 13.33 \\
\hline At discharge & 136.46 & 6.57 & 139.43 & 7.22 \\
\hline
\end{tabular}

The mean values of diastolic blood pressure at the time of admission in hypertensive urgency were found to be $122.55 \mathrm{mmHg}$ and the mean values after treatment were $88.46 \mathrm{mmHg}$ a mean change of $34 \mathrm{mmHg}$. In the hypertensive emergency group, the mean values at the time of admission were $130.83 \mathrm{mmHg}$ and at the time of discharge, the values were $89.06 \mathrm{mmHg}$ a mean change of $41 \mathrm{mmHg}$. The DBP recordings during various stages of treatment are shown in table 5.

Table 5: Showing the recording of Diastolic Blood pressure during various stages of treatment

\begin{tabular}{|l|c|c|c|c|}
\hline \multirow{2}{*}{$\begin{array}{l}\text { DBP recordings during } \\
\text { various stages of treatment }\end{array}$} & \multicolumn{2}{|c|}{$\begin{array}{c}\text { Hypertensive urgency } \\
(\mathbf{N = 2 7})\end{array}$} & \multicolumn{2}{c|}{$\begin{array}{c}\text { Hypertensive Emergency } \\
(\mathbf{N}=\mathbf{2 0})\end{array}$} \\
\cline { 2 - 5 } & $\begin{array}{c}\text { Mean Diastolic } \\
\text { Blood pressure } \\
\text { mmHg }\end{array}$ & $\begin{array}{c}\text { Standard } \\
\text { deviation }\end{array}$ & $\begin{array}{c}\text { Mean Diastolic } \\
\text { Blood pressure } \\
\text { mmHg Mean }\end{array}$ & $\begin{array}{c}\text { Standard } \\
\text { deviation }\end{array}$ \\
\hline At the time of admission & 122.55 & 11.32 & 130.83 & 15.66 \\
\hline After one hour & 109.23 & 15.40 & 112.52 & 18.74 \\
\hline At the end of 24 hours & 95.95 & 10.55 & 97.11 & 12.28 \\
\hline At discharge & 88.46 & 5.54 & 89.06 & 6.13 \\
\hline
\end{tabular}

ECG findings in the patients with hypertensive emergency indicate Left ventricular hypertrophy in $\mathrm{n}=10(50 \%)$. This finding was found to be significantly present in patients with hypertensive emergencies as compared with hypertensive urgency. ST-T changes were found in $\mathrm{n}=4(20 \%)$ patients with hypertensive emergencies. More than one end-organ damage was found in $\mathrm{n}=8(20 \%)$ cases of hypertensive emergency. Pulmonary edema was found in $n=6(30 \%)$ of cases of hypertensive emergency and the $p$ values were found to be significant. The other details are shown in table 6.

Table 6: Showing the lab investigations and findings in the cases of study

\begin{tabular}{|l|c|c|c|}
\hline Investigation & $\begin{array}{c}\text { Hypertensive Urgency } \\
(\mathbf{N = 2 7 )}\end{array}$ & $\begin{array}{c}\text { Hypertensive Emergency } \\
(\mathbf{N}=\mathbf{2 0})\end{array}$ & P values \\
\hline Electrocardiogram [ECG] & $1(3.70 \%)$ & $10(50 \%)$ & $<0.01^{*}$ \\
\hline Left Ventricular Hypertrophy LVH & $0(0.00)$ & $4(20 \%)$ & 0.12 \\
\hline ST-T changes & $1(3.70 \%)$ & $4(20 \%)$ & 0.33 \\
\hline Chest X-ray & $0(0.00)$ & $6(30 \%)$ & $<0.05^{*}$ \\
\hline Cardiomegaly &
\end{tabular}

*Significant 


\section{Discussion}

The present study was conducted in a Teaching Medical College Hospital one of the tertiary care centers. In this study, we found the number of male patients $n=31(65.96 \%)$ of patients with hypertensive crisis. Martin et al ${ }^{[8]}$ in their study found a hypertensive crisis in 55\% of male patients which indicates that there is slight male preponderance for the hypertensive crisis to occur in male patients. A similar observation was also made by and Zampaglione et al; ${ }^{[6]}$ with a higher number of males in hypertensive crisis. There is a greater incidence of target organ damage that occurs in male which was also revealed by Framingham study ${ }^{[9]}$ that revealed that the incidence of coronary arterial disease in men tends to increase linearly with age. In this study, the target organ damage was found in $n=8(20 \%)$ cases of hypertensive emergency. Analysis of symptoms of the patients in the present study revealed the hypertensive urgency group presented with giddiness in $\mathrm{n}=17(62.96 \%)$ followed by headache in $n=15(55.56 \%)$. In a hypertensive emergency, group headache was found in $\mathrm{n}=11(55 \%)$ and giddiness was found in $n=9(45 \%)$. The neurological deficits in the present study were found in $n=7(35 \%)$ of patients of the hypertensive emergencies they included convulsions in $n=4(20 \%)$, hemiparesis in $n=3(15 \%)$. Martin et al; [8] found the presenting symptoms were of neurological deficit in $48 \%$ of cases followed by dyspnoea in $24 \%$ and chest pain in $20 \%$. Broderick $\mathbf{J}$ et al; found that hemiparesis was seen in a large number of patients with neurological deficit. Sanjay VP et $a ;^{[10]}$ in a similar study showed the presence of hemiparesis in $75 \%$, convulsions in $16.6 \%$ and visual deficits in $8.3 \%$ of the patients. Most of the patients $n=40(85.1 \%)$ in the present study were previously known hypertensive. Some had ignored medications for the previous few days. Garcia GM et al; ${ }^{[11]}$ noticed a large number of patients, $(65.9 \%)$, in their study to be previously diagnosed hypertensive. Therefore hypertensive emergencies are more likely to occur in patients with previously known hypertension. The risk of hypertensive emergency increases in patients if they do they not adhere to antihypertensive medications ${ }^{[12]}$. Some other factors like emotional stress and daily activities and interactions with other medications are also known to precipitate hypertensive emergency. A study of risk factors in the present study revealed in the cases of hypertensive urgency was dyslipidemia in $\mathrm{n}=5(18.51 \%)$, followed by diabetes mellitus in $\mathrm{n}=3(11.11 \%)$. Similarly, in hypertensive emergencies, the common risk factor was diabetes mellitus followed by dyslipidemia in $\mathrm{n}=6(30 \%)$ of cases. The highest recorded systolic blood pressure in the hypertensive emergency was $230 \mathrm{mmHg}$ and mean systolic blood was $201.02 \pm$ $22.68 \mathrm{mmHg}$ and the highest diastolic pressure was $150 \mathrm{mmHg}$ the mean was $130.83 \pm 15.66$ $\mathrm{mmHg}$. The mean reduction of BP at the time of discharge of SBP was by $62 \mathrm{mmHg}$ and DBP was by $41 \mathrm{mmHg}$. It was found that higher levels of blood pressure were in patients with more than one target organ damage. The investigations showed the presence of LVH more significantly in hypertensive crisis, it also showed the significant number of cases with pulmonary edema in hypertensive crisis as compared to hypertensive urgency. Patients with a hypertensive emergency are a greater risk of complications hence prompt recognition and management are essential for preventing morbidity and mortality.

\section{Conclusion}

Within the limitations of the present study, it was found that hypertensive crisis is found more commonly in $6^{\text {th }}$ to $7^{\text {th }}$ decade of age. There is the tendency of males to have a higher incidence of hypertensive crisis. Known hypertensive with some degree of target organ damage is more associated with hypertensive emergencies. Therefore strict blood pressure control and regular evaluation of the patients is necessary to prevent morbidity and mortality due to hypertensive crisis.

Conflict of interest: None

Source of support: Nil

Ethical Permission: Obtained 


\section{Reference}

1. Global Health Observatory (GHO) data available online from [https://www.who.int/gho/ncd/risk_factors /blood_pressure_prevalence_text/en/] Accessed on 19/8/2019.

2. Dan Longo Anthony Fauci Dennis Kasper Stephen Hauser J. Jameson Joseph Loscalzo Harrisons principles of internal medicine, $18^{\text {th }}$ edition $2011 ; 18 ; 2: 247$.

3. Karras DJ, Ufberg JW, Harrigan RA, Wald DA, Botros MS, McNamara RM. lack of relationship between hypertension associated symptoms and blood pressure in hypertensive emergency department patients. American journal of emergency medicine.2005;23(2): 106-110.

4. Chobanian AV, Bakris GL, Black HR, Cushman WC, Green LA, Izzo JL Jr, et al. The Seventh Report of the Joint National Committee on Prevention, Detection, Evaluation, and Treatment of High Blood Pressure: the JNC 7 report. JAMA 2003; 289.

5. Volhard F, Fahr T. Die brightsche Nierenkranbeit: Klinik, Pathologie und Atlas. Berlin: Springer;1914;1(1):11.

6. Zampaglione B, Pascale C, Marchisio M, Cavallo-Perin P. Hypertensive urgencies and emergencies. Prevalence and clinical presentation. Hypertension 1996; 27(1):144-47.

7. Ventura HO, Mehra MR, Messerli FH. Desperate diseases, desperate measures: tackling malignant hypertension in the 1950s. Ame Heart J. 2001 Aug 1;142(2):197-03.

8. Martin JF, Kuniyoshi CH, Andrade LG, Yugar-Toledo JC, Loureiro AC, Cipullo JP. Fatores preditores de mortalidade em pacientes com crise hipertensiva. Arq Bras Cardiol. 2007;89(Suppl 1):201-01.
9. Cameron JS, Hicks J. Frederick Akbar Mahomed and his role in the description of hypertension at Guy's Hospital. Kidney Int. 1996; 49:1488-06.

10. Sanjay V. Patne, Kailas N. Chintale, S. Tungikar, Pravin Dhadse, Sandip R. Dukare. Clinical study of hypertensive emergencies in young patients in tertiary health care center. Asian Pac. J. Health Sci., 2016; 3(1):7-15.

11. Gracia GM, Miudo V, Manuel Lopex CdaG, Vassuelela Gomex J. Characterization of patients aged 45 or under admitted with hypertensive emergencies in the Hospital do Prenda.2012;3(4):112.

12. Gupta R. Trends in hypertension epidemiology in India. Journal of Human Hypertension 2004;18:73-78. 